\title{
Research on the Path with Low-carbon Electricity System Formed under the Smart Grid
}

\author{
Ling Wang \\ Benxi Power Supply Branch, State Grid Liaoning Electric Power Supply Co. Ltd \\ Benxi, china \\ bxwl_wl@163.com
}

\begin{abstract}
The development trend of the world on a low carbon economy and green safe and reliable operation of the power system of the country's economic development put forward higher requirements, how to respond and adapt to changes in the external environment, to form a functional, reliable, viable mechanisms for low-carbon electricity system becomes the current important issues need to be answered. Building a low carbon economy and the development of traditional power systems present new challenges, how to achieve power system development mode shift ring in the new low-carbon economy is the current condition of the core issues that must be answered. From the point of view of reliability guarantee security of supply, low-carbon electricity system analyzes the basic functions required of proposed advanced smart grid technologies in support, according to cleaner production, reduce losses, investment optimization and other aspects of the smart grid to support specific path to achieve low-carbon electricity system.
\end{abstract}

Keywords- smart grid; carbon; power systems; path

\section{INTRODUCTION}

Global warming is one of the greatest challenges currently facing the human society. To mitigate global warming, reduce the harm caused by climate change, the International Energy Agency (IEA) pointed out that in 2050, the world's greenhouse gas emissions should be reduced by at least 50 percent below 1990 emission levels[1-3]. This is an urgent need for the world to cooperate with action. The key to the whole energy system transition to low-carbon energy systems is how the power system to low-carbon electricity system transition. In the meantime, if you want to other industries such as transportation industries to reduce carbon emissions, you need to promote the use of electric vehicles and the like. Thus, the total demand for electricity will increase, but the total could increase carbon emissions may be reduced, depending on the effect of carbon emissions which better links (links or terminal power generation alternative link) to achieve[4-5]. China's power production of primary energy use coal-based, more than 70 percent of the power structure composed by coal, $\mathrm{CO}_{2}$ emissions intensity of electricity production units is approximately $0.82 \mathrm{~kg} /(\mathrm{kW} \cdot \mathrm{h})$, far higher than the global and developed countries average; meanwhile, generators tend to have a longer service life, which makes China's power industry has a strong carbon lock-in effect, that $\mathrm{CO}_{2}$ emissions within the industry for a long period of time will be locked the current power structure of the future. Therefore, the scientific power structure of China's power industry will be able to effectively implement low carbon development play a crucial role[6].

Therefore, to achieve increase in the share of non-fossil energy consumption and reduce $\mathrm{CO}_{2}$ emissions intensity of the dual goals under the current opportunities in the rapid development of the smart grid, electric power industry to develop mechanisms to adjust their response to changes in the external environment, the smart grid should play what kinds of action to promote energy-saving emission reduction targets, thus ensuring the sustainable development of socio-economic environment is an important proposition of the current need to be answered. Therefore, this article analyzes the introduction of technology and economic incentives and other types of lowcarbon elements in the traditional mode, target mode power supply planning, analysis of the path to achieve low-carbon electricity system; On this basis, reveals a low-carbon Under the concept of development, smart grid power systems for the formation of a low-carbon path to achieve a supporting role.

\section{ACHIEVE THE GOAL OF LOW-CARBON POWER SYSTEM MODEL}

Modern society can not do without electricity, a safe, stable and reliable power supply is essential for all types of users. In the process of the formation of the transition to low-carbon power system, the power system must continue to maintain a high level of supply reliability. To achieve a high level of power system reliability, the need to determine the optimal level of reserve capacity of a system that seeks a balance between supply reliability and cost of electricity, the cost (marginal value of generating capacity) in spare capacity and spare capacity of the value system of supply reliability (available power loss to evaluate) a trade-off between. Methods for assessing the reliability of the value of each country vary, the UK energy market in the manual that part of the electricity demand in the power supply has not been determined by evaluating the reliability of power supply users, but does not include that portion of the user voluntarily reduce electricity needs. Determine the relationship between the marginal value of generating capacity between EEU that an optimal spare capacity issues, for the purposes of a power system reliability is not high enough, when the two benefits in any small change in the time will give the system caused great impact[7]. For a while the high reliability of power supply system, if we continue to increase the reserve capacity, the system will make 
the total cost of electricity increased significantly. But for China, the status of the system should not be based solely on the marginal capacity to identify and assess the reliability of power supply. Because electricity generation in the system constitute large changes, the relationship between value and the EEU marginal capacity will change. In order to achieve the ratio of the proportion of non-fossil energy consumption target of future domestic renewable and clean energy generation capacity is growing, and different renewable energy generation capacity of these features, such as the power to issue multiple wind farms may have relevance, assess the reliability of the feeding method is not science[8].

Therefore, to ensure a high level of supply reliability, researchers reasonable, effective reliability assessment techniques is the problem of domestic future low-carbon electricity system formation process must earnestly consider. During the transition to a low carbon economy, ensure energy security of supply is the most important low-carbon electricity system, need to meet a series of factors or conditions, including: (1) there must be sufficient, increasing capacity for low-carbon generators power generation and supply, and the system must have an appropriate level of reserve capacity; (2) generation capacity and power generation fuel sources must be reliable enough to ensure that at any time to meet fluctuating demand for electricity; (3) constitute power generation capacity and fuel diversification should be possible to ensure that certain types or classes of power generation capacity of the fuel shortage will not threaten the safety and security of electricity supply system operation; (4) market should be able to give effective price signals, and allows members to market price signals for this timely and effective response, so as to ensure that the system to minimize the imbalance.

From the international point of view, "UK Low Carbon Transition Plan," the British government recently enacted noted the situation, the transition to a low carbon economy is a major feature 21 century economic development. US federal and some state governments have also introduced a number of "renewable energy grid rules" require power companies to accept all kinds of clearance; Kyrgyz energy generation capacity Internet, in order to reduce the proportion of the corresponding fossil energy generation[9].

Is currently speeding up the development of China's "Twelfth Five Year Plan", in which energy planning, renewable energy, smart grid planning and planning are the clear; the development of Kyrgyzstan and renewable energy sources and grid planning as an important content, in order to achieve goal of reducing carbon emissions. We believe that to achieve these carbon emissions will not hinder the transition plan reform of the electricity market, and also need to market forces to achieve this carbon reduction plan. But relying on the market mechanism is not enough, while the government needs to play a strategic role, namely carbon pricing policies that promote technological progress: Provides information for power generation companies and electricity companies and guide them the right decisions, to take measures to maintain energy security Supply; protection of vulnerable groups as well as making market opportunities maximized, and so on.
Therefore, whether developed or developing countries, only the government will be able to promote the transition to a lowcarbon, only the government will be able to promote such a fundamental change in the power system. In addition, requiring the government to promote the development of key low-carbon technologies, these low-carbon technologies, including renewable energy generation, nuclear power and carbon capture and sequestration technology. Government should respect the current electricity market (including power operating system) development and implementation of some important reforms (innovation) plan, and to gradually form a smart, low-carbon electricity system.

In the future low-carbon electricity system conditions, almost all of the plants must be clean energy or fossil fuel plants fitted with carbon capture and storage device, or when the emergence of new low-carbon technologies power plants. When the size and characteristics of the electricity demand for electricity will be a great change. Then it is possible to use lowcarbon energy sources in terms of heating and transportation. To do this, you will need a larger capacity of the grid, and the larger capacity of the grid to be able to meet the needs of the new generation of these technologies to be able to effectively control Ha greater fluctuations in energy supply (Park for renewable energy generation Most of intermittent power generation, such as wind and solar power) or greater energy demand fluctuations.

By analyzing the study shows that during the transition to a low carbon economy, ensure energy security of supply there are several factors that need to meet or conditions, which include: (1) there must be enough low-carbon generators increasing capacity for power generation and supply, and system to have a proper level of spare capacity. (2) as well as its power generation capacity of the fuel source must be sufficiently reliable to ensure that at any time to meet fluctuating demand for electricity. (3) constitute a power generation capacity of the fuel composition and should be as diversified to ensure the system does not threaten the safety and security of electricity supply to run a manure shortage of generation capacity or type of fuel for power generation. Viagra diversify generation capacity configuration refers to the system should have a variety of power generation technology, and power generation fuel diversification refers to the fuel supply should be decentralized. (4) the market should be able to give effective price signals, and allows members to market price signals for this effective response in a timely manner, so as to make the system to minimize the imbalance.

\section{PATH TO ACHIEVE LOW-CARBON ELECTRICITY SYSTEM}

Low-carbon electricity system depends on planning, establishing technical, operational and electricity and other four kinds of key mechanisms, as well as cleaner production and intelligent running two aspects of "de carbon" transformation. Establish four kinds of key mechanisms, first of all from the roots energy strategic planning, development and utilization of structural changes in the domestic energy, strengthen the renewable energy and clean energy development planning coordination, in accordance with the "big plan, low carbon planning and green planning" The idea to build "low-carbon energy development planning mechanism"; secondly, to low- 
carbon power generation technology as a breakthrough in research has been the basis of further large-scale development of renewable energy generation technologies (such as wind power, solar energy photovoltaic solar thermal power technology ) and conventional thermal power of carbon capture and storage technologies, from the perspective of the pilot run, promote the use of integrated layout, build "low-carbon electricity technology development mechanism"; the third is supporting the demand for large-scale renewable energy generation resources and network building strong and smart grid systems, address and resolve problems similar to contribute significantly intermittent wind and solar power has, the use of smart grid technology to build "low-carbon electricity smart operation mechanism"; Fourth, a large number of low-carbon generation and network operation resources, particularly renewable energy and nuclear power output and power output of the model does not match the pattern of demand, coupled with the continuous development of future smart cities, smart energy use and the emergence of intelligent transportation systems, heating and transportation industry to switch to electricity, so electricity demand model system will change dramatically, in response to the above adjustments and changes in consumption pattern of the problems caused by the need to build "smart power low-carbon electricity system."

Two aspects of the "de-carbon" into the side of pluralism, including power generation and grid cleaner production aspects of the intelligence operation. First, diversification of clean power generation side of the production. (1) government needs to develop and implement incentive mechanisms and supporting policies to guide the generation of investors to invest in low-carbon generation technologies, making the generation side consists of a variety of power generation technology, power generation and power generation fuel diversification constitute diversification; (2) new emerging low-carbon electricity system, the need for decision-making and review process of generating carbon reduction projects to provide an efficient, open and transparent, workable structure and system planning, and investors may be able to make the project more accurately predict how the economic returns of their investments, to attract investors for investment in lowcarbon generation technologies; (3) need to introduce a series of initiatives to support the development of renewable and clean energy; (4) low-carbon economy in the future, fossil fuel power generation can be neglected, because in the domestic power structure in fossil fuels will continue to play an important role in the next longer period of time. Second, part of the intelligent grid to run, you need to study and solve problems based on the generation side after the "go carbon", how to match supply and demand in the system, and how to ensure the transmission and distribution of electrical energy and other aspects. At this point the power supply is renewable and clean energy generation intermittent impact distribution system as well as the difficulty of balancing energy supply and demand will increase energy. Chinese wind power is rich in resources, the current requirements of the community as soon as possible and let the wind power on a large scale and network operation.

For this problem, in the future of low-carbon electricity system construction and development process, you first need to take measures to reform the management of the grid, while the technical standards and networks for further research, and increase investment in the transmission grid to improve acceptance renewable energy generation capacity and networks secondly, to speed up the construction and development of the smart grid, energy supply and energy interact between the needs of the existing grid. Smart Grid has some obvious advantages, but in the context of the use of low-carbon economy of these advantages of smart grid technologies can help to achieve sustainable, low cost and safe supply of goals. These advantages include: (1) for renewable and clean energy generation and other low-carbon power generation and network operation to provide technical support, and hardly any of those previous generation capacity of the region, you can take advantage of the extensive use of smart grid technology for renewable and clean energy generation ; (2) can efficiently and reliably overcome intermittent electricity demand and the volatility of renewable and clean energy generation to contribute to the adverse impact of power system security and stability arising, improve the reliability of the power supply system level; (2) it can help the user to adjust its electricity demand (mode), thus reducing electricity costs, and can help the user to get the revenue from the sale of electricity generation micro turbines are owned by.

\section{SMART GRID POWER SYSTEMS TO SUPPORT THE FORMATION OF A LOW-CARBON PATH TO ACHIEVE}

Based on the above analysis of the smart grid target function can be found in the smart grid has significant energy saving properties, for the promotion of low-carbon power system has an important supporting role. Specifically, the energy saving benefits of smart grid there are direct and indirect points. Direct energy efficiency means reducing fossil fuel directly from the source (carbon-based energy sources, including coal, oil, natural gas) consumption size; indirectly through increased energy efficiency refers to end-use energy efficiency, reduce process losses arising from electricity savings, thereby reducing The source of the energy use of the size; direct emission reduction benefits is due to the reduction in energy use by reducing the source of emissions $\mathrm{CO}_{2}$; indirect emission reduction benefits is through the optimization of the investment, the implementation of more energy efficiency projects, and thus bring the emission reduction benefits .

According to the relevant documents of domestic smart grid construction planning, smart grid technology standard system and other aspects of domestic electricity generation, transmission and distribution, with each link can support lowcarbon electricity system implementation of smart grid technologies include the following 10: wind power technology, Solar power generation and network technology, advanced transmission technology, smart grid scheduling technology, distributed generation and micro-grid technology, energysaving technology and advanced buck voltage control technology, the power of information feedback system technology, energy efficiency and demand response, smart Architecture Festival electrical diagnostic measurement technology, electric cars electricity load management techniques. 
Large-scale wind power technology, large-scale solar power generation and network technology development, laying the foundation for clean energy production. Smart grid technology is to enhance the scheduling and dispatching system to manage large power grid and the ability to optimize the allocation of resources, in-depth risk defense capability, scientific decision management capabilities, flexible and efficient technology infrastructure capacity and fair regulation of the market-friendly deployment capabilities. And intelligent scheduling technology, large-scale renewable energy that can be implemented in an appropriate location for power generation, to realize the optimization of traditional fossil energy alternatives, to reduce carbon-based energy consumption results from the power source. Distributed generation and micro-grid technology for the formation of the load terminal power mode, in addition, a multi-generation resources such technologies for clean energy, also directly reduce the use of carbon-based energy.

The whole process from electricity production to use the term, reduce the loss of energy saving path includes three segments based on the path. (1) power generation sector to achieve low-carbon path to reduce wear and tear on electricity. Based smart grid scheduling technology, can arrange as clean energy generation and reduce abandoned wind, water and other power generation abandoned waste of resources, so as to achieve the purpose of indirect energy savings and indirect emissions. (2) transmission path based sectors to achieve reduced loss of low-carbon electricity. Application of advanced transmission technology to reduce energy loss during transmission to achieve energy savings and indirect indirect emissions. (3) distribution sectors to achieve low-carbon path to reduce wear and tear on the power. Through advanced automation system will be seamlessly integrated into a large number of distributed power grid and coordinated operation, will reduce the long-distance transmission link for energy during power loss, to achieve the purpose of indirect and indirect energy saving and emission reduction.

Optimized to achieve low-carbon electricity investment is closely related to the path on the other three paths. The path for the implementation process, and reduce end-use energy efficiency improvement of electricity transmission link loss can be reduced to the source of power generation capacity of investment demand, as well as the power system transmission expansion investment needs. Investment savings can be used for the development of new energy efficiency projects, thereby further improving the energy efficiency of the system to achieve indirect energy saving, indirect reduction purposes.

\section{CONCLUSION}

Innovative low-carbon development trend of globalization and smart grid technologies, prompting the emergence and development of low-carbon electricity system, and a high level of protection of the basic elements of supply reliability is lowcarbon electricity system implementation. Low-carbon power system, is a short-term measures and long-term mechanisms for coordination, technical means and management tools to match units, the construction and development related to all aspects of energy production, transmission and consumption, and a comprehensive system of road. Objective function of the smart grid has significant energy saving and clean development role, based on the target function of the smart grid, based on clean production, reduce losses, end-saving and low-carbon electricity system to optimize the realization of the investment path.

\section{REFERENCES}

[1] IPCC. Intergovernmental panel for climate change(IPCC) fourth assessment report. Cambridge, UK: Cambridge University Press, 2007.

[2] Grubb. M, Jamasb. T, Pollitt. M. G, "Delivering a low-carbon electricity system," Cambridge, UK: Cambridge, University Press, 2008.

[3] JAMASB T, NUTTALL W J, POLLITT M G, "Future electricity technologies and systems," Cambridge, UK: Cambridge University Press, 2008.

[4] Sovacool Benjamin K, "Replacing tedium with transformation: Why the US Department of Energy needs to change the way it conducts longterm R\&D,” Energy Policy, vol. 36, pp. 923-928, April 2008.

[5] Mcdonald. J, “Adaptive intelligent power system: active distribution networks ," Energy Policy, vol. 36, pp. 4346-4351, Dec 2008.

[6] Skea. J, "Delivering a low-carbon electricity system ," Energy Policy, vol. 15, pp. 564-573, Jan 2011.

[7] Viebahn. P, Nitsch. J, Fischedick. M, et, al, "Comparison of carbon capture and storage with renewable energy technologies regarding structural, economic, and ecological aspects in Germany ," International Journal of Greenhouse Gas Control, vol. 1, pp. 121-133, Jan 2007.

[8] Kang. C. Q, Chen. Q. X and Xia. Q, "Prospects of low-carbon electricity," Power System Technology, vol. 33, pp. 1-7 Feb 2009.

[9] M. Young, The Technical Writer's Handbook. Mill Valley, CA: University Science, 1989. 